\title{
A rare cause of severe non-diabetic hypoglycaemia
}

\section{ABSTRACT}

A 67-year old woman presented with an unwitnessed fall and decreased oral intake. She had a learning disability, hypertension, epilepsy, asthma, chronic iron deficiency anaemia, mild lymphopenia, osteoporosis and treated uterine cancer. After clinical review, she was treated for Hospitalacquired pneumonia (following a recent hospital admission) with possible aspiration. She was noted to have hyponatraemia secondary to dehydration. She was commenced on intravenous Levofloxacin and Metronidazole along with supportive care, based on antibiotic guidance due to her known allergy to penicillin. On day 3 of admission, she was found unresponsive with a capillary blood glucose of $0.6 \mathrm{mmol} / \mathrm{L}$, which improved with $10 \%$ glucose infusion. The low blood glucose was attributed to poor oral intake. However, her serial blood sugar results demonstrated persistent hypoglycaemia for $72 \mathrm{~h}$ needing further intravenous glucose infusions. A medication review was undertaken and Levofloxacin was discontinued. After $24 \mathrm{hrs}$ of discontinuation, the hypoglycaemic episode resolved. A short synacthen test showed a normal cortisol response. There were no further episodes of hypoglycaemia.

Conclusion

As her persistent hypoglycaemia resolved on discontinuation of Levofloxacin, a diagnosis of fluoroquinolone induced hypoglycaemia was reported to MHRA. Fluoroquinolones are thought to induce hypoglycaemia by increasing the insulin release via blockade of adenosine triphosphate-sensitive $\mathrm{K}^{+}$channels in the $\beta$ cells of the pancreas. This effect may not be clinically evident in all patients because of physiologic mechanisms that regulate blood glucose levels. Health professionals should be aware of the potential risk of severe hypoglycaemia with the use of Fluoroquinolones which are a first or second-line treatment for common infective processes. Fluoroquinolones should be stopped immediately and switch to a non-Fluoroquinolones antibiotic if possible. In elderly patients with compromised oral intake or in those with other comorbidities, regular blood glucose monitoring should be carried out to avoid life-threatening hypoglycaemic episodes.

Keywords; Hypoglycaemia; fluoroquinolones; Levofloxacin

$\underline{\text { Introduction }}$
Nondiabetic Hypoglycaemia
Laju Etchie MBBS, Devaka

Fernando MD FRCP MSc, Ashok

Poduval MBBS MRCP, Vakkat

Muraleedharan MD FRCP PhD

Sherwood Forest Hospitals NHSFT, UK

Correspondence to: laju.etchie@nhs.net

Cite as: Etchie, L., Fernando, D., Poduval, A., Muraleedharan, V. A rare cause of severe nondiabetic hypoglycaemia. The Physician Vol 6: Issue 3: epub 08.05.21 DOI https://doi.org/10.38192/1.6.3.12

Article Information

Submitted 22.11.20

Peer reviewed 24.1.21

Revised 28.3.21

Published 8.5.21

ISSN 2732-513X (Print)

ISSN 2732 - 5148 (Online)

OPEN 2 ACCESS (C) () (5) 
Hypoglycaemia is a clinical syndrome present when the blood glucose concentration falls below the normal fasting glucose range. Whipple's triad should be present in cases of true hypoglycaemia: hypoglycaemic symptoms, accompanying low blood glucose concentration, and resolution of symptoms after raising the blood glucose concentration to normal. ${ }^{1}$ Hyperinsulinaemic hypoglycaemia is not common in the general population, while iatrogenic or factitious hypoglycaemia is seen to be a more common occurrence among those with access to glucoselowering agents. ${ }^{2}$

Symptoms of hypoglycaemia can be categorised as neuroglycopenic (the result of brain glucose deprivation) or neurogenic / adrenergic/ autonomic (the result of the persons perception of physiological changes caused by the sympathoadrenal discharge triggered by hypoglycaemia). ${ }^{3}$

Autonomic symptoms occur at plasma glucose concentrations of approximately $60 \mathrm{mg} / \mathrm{dL}$ $(3.3 \mathrm{mmol} / \mathrm{L})$ whereas neuroglycopenic symptoms occur at plasma glucose concentrations of approximately $50 \mathrm{mg} / \mathrm{dL}(2.8 \mathrm{mmol} / \mathrm{L})$ or less. ${ }^{4}$

Hypoglycemia is relatively uncommon in people without diabetes and commonly occurs in the setting of the treatment of glucose lowering agents such as sulfonylureas or insulin.

Diagnostic values for non-diabetic hyperinsulinemia are a plasma insulin concentration of at least $18 \mathrm{pmol} / \mathrm{L}$, plasma C-peptide concentration of at least $0.2 \mathrm{nmol} / \mathrm{L}$, proinsulin concentration of at least $5.0 \mathrm{pmol} / \mathrm{L}$, beta hydroxybutyrate when the fasting plasma glucose is less than $3 \mathrm{mmol} / \mathrm{L}^{5}$

Hypoglycemia can be caused by insulin secreting pancreatic islet cell tumours and non islet cell tumours secreting IGF II. It can also be accidental, surreptitious, or even malicious. Hypoglycemia can occur as a result of hyperinsulinism after Roux-en- $Y$ gastric bypass for obesity. It can also be caused by an antibody to insulin, drugs are the most common cause of hypoglycaemia. Hypoglycaemia sometimes occurs during sepsis and in other critical illnesses including renal or hepatic failure, and rarely in cortisol deficiency.

Many drugs in addition to insulin, insulin secretagogues, and alcohol have been reported to cause hypoglycaemia. ${ }^{6} \quad$ Medications causing hypoglycaemia include Insulin, fluoroquinolones, angiotensin converting enzyme inhibitors (especially captopril), beta-blockers and oral hypoglycaemic agents to mention a few. ${ }^{7}$
Mortality and morbidity associated with hypoglycaemia

The immediate effect of hypoglycaemia is manifest in multiple systems including musculoskeletal (patients could have accidents, falls, fractures), cardiovascular (myocardial infarction, cardiac arrythmias) and neurological (seizures, coma and cognitive dysfunction). ${ }^{8}$ There is increased in-hospital and postadmission mortality risk in patients with blood glucose levels of $<3.0 \mathrm{mmOl} / \mathrm{l}(70 \mathrm{mg} / \mathrm{dl})$, with and without insulin therapy when compared to those without hypoglycemia. ${ }^{9}$

Hypoglycaemia promotes platelet aggregation, decreases partial thromboplastin time, lowers platelet count, increases fibrinogen and factor VIII in type 1 diabetes patients. These alterations on the coagulation cascade-related factors could have significant effects on the cardiovascular system, contributing to major vascular events such as myocardial infarction or stroke. The hypoglycaemic state also causes lengthening of the corrected QT interval and increased QT dispersion during cardiac repolarization which leads to life threatening arrythmias such as ventricular tachycardia or sudden death with ventricular fibrillation. ${ }^{10}$

Hypoglycaemia is commonly encountered in the treatment of diabetes with glucose-lowering medications, but there are other less common causes which can lead to significant morbidity. Therefore awareness of such causes, their diagnosis and prompt treatment is important to prevent sequelae of prolonged hypoglycaemia that may result in irreversible neurological or cardiac sequelae.

We report a case of Levofloxacin induced hypoglycaemia. Levofloxacin is widely used to treat different types of bacterial infections and its potential risk of causing hypoglycaemia is significant to avoid its related effect on morbidity and mortality.

\section{Case Report}

A 67-year-old woman presented with an unwitnessed fall and decreased oral intake. She had a background of learning disability, hypertension, epilepsy, bronchial asthma, chronic iron deficiency anaemia, chronic mild lymphopenia, osteoporosis and previously treated uterine cancer. Her regular medications were oxybutynin, folic acid, ferrous fumarate, phenobarbitone, paracetamol, buprenorphine patch 
and senna. At the time of admission, she was resident with her mother in a house with carers going to see her times a day. She used a walking frame and sometimes a wheelchair.

After clinical review, a provisional diagnosis of hospital acquired pneumonia (following her recent hospital admission) was made. Her clinical condition was complicated with suspected aspiration along with hyponatraemia secondary to dehydration.

Her chest $x$-ray showed persistent radio-opacification in the right lung zone. She was to be allergic to Penicillin. Our hospital antibiotic guideline for Hospital Acquired Pneumonia and Aspiration recommended treatment with Levofloxacin and Metronidazole. She was commenced on intravenous levofloxacin $500 \mathrm{mg}$ 12 hourly and metronidazole $500 \mathrm{mg} 8$ hourly along with supportive care. Her CURB-65 score was 2 (Blood pressure 96/45 $\mathrm{mmHg}$ and Age- 67 years).

On Day one, her random venous blood glucose was noted to be $7.1 \mathrm{mmol} / \mathrm{L}$. She was not known to have diabetes. On day 3 of admission, she was found to be unresponsive with an elevated Early warning score (4), capillary blood glucose was found to be $0.6 \mathrm{mmol} / \mathrm{L}$, which improved with an infusion of $10 \%$ glucose. The low blood glucose was attributed to poor oral intake. Her serial blood sugar monitoring continued to demonstrate persistent hypoglycaemia, requiring further doses of intravenous glucose.

A medication review was undertaken, and levofloxacin was discontinued. After $24 \mathrm{hrs}$ of discontinuation, the hypoglycaemic episode resolved. The nursing and medical staff expressed concern about her food intake and a possible risk of compromised nutrition. She was reviewed by our swallowing assessment team and she was placed on puree diet.

Her serial capillary blood glucose is shown in figure 1. A short Synacthen test cortisol response (At 0min -262nmol/l, 30mins$467 \mathrm{nmol} / \mathrm{l})$.

She was observed for hypoglycaemia during the remainder of her inpatient stay with serial capillary blood sugar monitoring and no further hypoglycaemic episodes were observed. Hence, a diagnosis of levofloxacin induced hypoglycaemia was considered, and no further investigation was undertaken.

\section{Discussion}

The Federal Drug Administration in the USA published a review of reports from Adverse Event Reporting System and the medical literature between 19872017, in which fluoroquinolones are said to have caused about 67 cases of life-threatening hypoglycaemic coma including 13 deaths and 9 permanent disabling injuries. Most of these cases were associated with levofloxacin.

Its hypoglycaemic effect is found to occur more in the elderly and those with diabetes using an oral hypoglycaemic agent or insulin. ${ }^{11}$ Fluoroquinolones have insulin secretagogue actions and have been shown in studies on rat islet cells, to induce hypoglycaemia by increasing the insulin release via blockade of adenosine triphosphate-sensitive $\mathrm{K}+$ channels in the $\beta$ cells of the pancreas. This effect may not be clinically evident in all patients because of physiologic mechanisms that regulate blood glucose levels. ${ }^{12,13}$

An experiment assessing the effects of three fluoroquinolone derivatives- Levofloxacin, Gatifloxacin and Temafloxacin demonstrated dose-dependent stimulation of insulin secretion and inhibition of pancreatic beta-cell ATP -sensitive $\mathrm{K}^{+}$channel activity. In a reconstituted system, Gatifloxacin and Temafloxacin inhibited Kir6.2 Delta C26 channels, which function in the SUR unit, indicating direct action of the drugs on the Kir6.2 subunits. These findings indicate that the stimulation of insulin secretion by inhibition of pancreatic beta-cell K(ATP) channels gives the fundamentals of the hypoglycaemia caused by certain fluoroquinolones. ${ }^{14}$ Gatifloxacin was taken out of the market on September $2^{\text {nd }}, 2008$ due to its association with potentially fatal blood sugar problems. $^{15}$

While the hypoglycaemic actions of many commonly used medications may not cause clinical hypoglycaemia de novo, they may cause hypoglycaemia in association with factors that facilitate and contribute to the risk of drug-induced hypoglycaemia. They include restricted food access, age, liver disease and renal disease. ${ }^{16}$ Our patient had no demonstrable evidence of reduced counterregulatory hormones such as hypothyroidism or hypoadrenalism.

We believe that the combination of reduced food access and the insulin secretagogue action of quinolones acted in synergy to contribute to our patient's hypoglycaemia.

\section{Conclusion}

Health professionals should be aware of the potential risk of severe hypoglycaemia in acutely ill patients with the use of frontline line antibiotics such as Fluoroquinolones which are treatment of choice for common infective processes. Glucose monitoring 
should be a part of safety surveillance when using these medications in elderly patients who are not having good oral intake or in those with other comorbidities, regular blood glucose monitoring should be carried out, when a Fluoroquinolones is used, to avoid life threatening hypoglycaemic episodes.

\section{References:}

1. Whipple AO. Islet cell tumours of the pancreas. Canadian Medical Association Journal 195266 334342.)

2. Non-Diabetic Hypoglycaemia. Best Practice, British Medical journal.

3. Towler DA, Havlin CE, Craft S, Cryer P 1993 Mechanism of awareness of hypoglycaemia. Perception of neurogenic (predominantly cholinergic) rather than neuroglycopenic symptoms. Diabetes 42:1791-1798.

4. Mitrakou A, Ryan C, Veneman T, Mokan M, Jenssen T, Kiss I, Durrant J, Cryer P \& Gerich J. Hierarchy of glycaemic thresholds for counterregulatory hormone secretion, symptoms, and cerebral dysfunction. American Journal of Physiology 1991260 E67-E74.

5. reference Cryer PE, Axelrod L, Grossman AB, Heller SR, Montori VM, Seaquist ER \& Service FJ. Evaluation and management of adult hypoglycaemic disorders: An Endocrine Society Clinical Practice Guideline. Journal of Clinical Endocrinology and Metabolism 2009 94 709-728. (doi:10.1210/jc.2008-1410.

6. MarksV, Teale JD1999 Drug-induced hypoglycaemia. Endocrinol Metab Clin North Am 28:555-577.

7. Mays H. Vue, PharmD and Stephen M. Setter, PharmD, CDE, CGP. Diabetes Spectrum 2011 Aug; 24(3): 171-177.

8. Impact of Hypoglycaemia on Morbidity and Mortality. Annals of Long-term Care. September 23, 2015.www.managedhealthcareconnect.com.
9. Amit Akirov, Alan Grossman, Tzipora Schochats, Ikin Shimon. Mortality Among Hospitalized Patients with Hypoglycaemia: Insulin Related \& Non-Insulin Related. The Journal of Clinical Endocrinology \& Metabolism volume 102, Issue 2, 1 Feb.2017. Pages 416-424.

10. Markolf Hanefold, Eva Duetting, Peter Bramlage. Cardiac Implications of Hypoglycaemia in Patients with Diabetes -A Systematic Review. Cardiovascular Diabetology. 12, Article number 135 (2013).

11. https://www.fda.gov/news-events/pressannouncements/fda-updates-warnings-

fluoroquinolone-antibiotics-risks-mental-health-andlow-blood-sugar-adverse

12. Sherrie L. Aspinall, Chester B. Good, Rong Jiang, Madeline McCarren, Diane Dong, Francesca E. Cunningham. Severe Dysglycaemia with the Fluoroquinolones: A Class Effect? Clinical Infectious Diseases, Volume49, Issue 3, 1 August 2009.

13. Maeda N, Tamagawa T, Niki I, Miura H, Ozawa K, Watanabe $\mathrm{G}$, et al. Increase in insulin release from rat pancreatic islets by quinolone antibiotics. $\mathrm{Br}$ J Pharmacol. 1996;117(2):372-6.

14. Saraya A, Yokokura M, Gonoi T, Seino S. Effects of Fluoroquinolones on insulin secretion and beta-cell ATP-sensitive $\mathrm{K}^{+}$channels. Eur J Pharmacol. 2004 Aug 16;497 (1):111-7 PMID: 15321742.

15. FDA: Tequin Was Withdrawn From U.S. Market "For Reasons Of Safety or Effectiveness" Drug Injury Watch. www.drug-injury.com. September 10, 2008.

16. Seltzer HS. Drug-induced hypoglycaemia. A review based on 473 cases. Diabetes 197221 955-966. (doi:10.2337/diab.21.9.955) 76 Seltzer HS. Druginduced hypoglycaemia. A review of 1418 cases. Endocrinology and Metabolism Clinics of North $\begin{array}{llll}\text { America } & 1989 & 18 & 163-183 .\end{array}$ (doi:10.2337/diab.21.9.955) 77 Fischer KF, Lees JA \& Newman JH. Hypoglycemia in hospitalized patients. Causes and outcomes. New England Journal of Medicine $\quad 1986 \quad 315 \quad$ 1245-1250. (doi:10.1056/NEJM198611133152002)).

Table 1 Results of Investigations:

Full Blood Count:

\begin{tabular}{|l|r|r|r|r|r|}
\hline Parameters & $31 / 07 / 20$ & $04 / 08 / 20$ & $05 / 08 / 20$ & $14 / 08 / 20$ & Reference Ranges \\
\hline $\mathrm{Hb}$ & 72 & 82 & 79 & 66 & $(115-165)$ \\
\hline $\mathrm{Wcc}$ & 10.1 & 3.9 & 2.6 & 4.0 & $(4-10)$ \\
\hline $\mathrm{Plt}$ & 251 & 182 & 188 & 215 & $(150-410)$ \\
\hline Hemat & 0.224 & 0.267 & 0.249 & 0.221 & $(0.36-0.46)$ \\
\hline
\end{tabular}




\begin{tabular}{|l|r|r|r|r|r|}
\hline Mcv & 80 & 86 & 83 & 97 & $(27-32)$ \\
\hline Neu & 9.2 & 3.2 & 1.6 & 3.0 & $(2.0-7.0)$ \\
\hline Lymph & 0.3 & 0.3 & 0.4 & 0.4 & $(1.0-3.0)$ \\
\hline CRP & 15 & 51 & 43 & 23 & $(0-5)$ \\
\hline Na & 122 & 130 & 128 & 135 & $(133-140)$ \\
\hline K & 5.6 & 4.9 & 4.7 & 4.5 & $(3.5-5.3)$ \\
\hline Urea & 6.5 & 4.4 & 2.6 & 3.5 & $(2.5-7.8)$ \\
\hline Creatinine & 66 & 57 & 55 & 57 & $(55-100)$ \\
\hline eGFR & 83 & $>90$ & $>90$ & $>90$ & \\
\hline
\end{tabular}

Figure 1: Capillary Blood Glucose:

\section{Serial Blood Glucose}

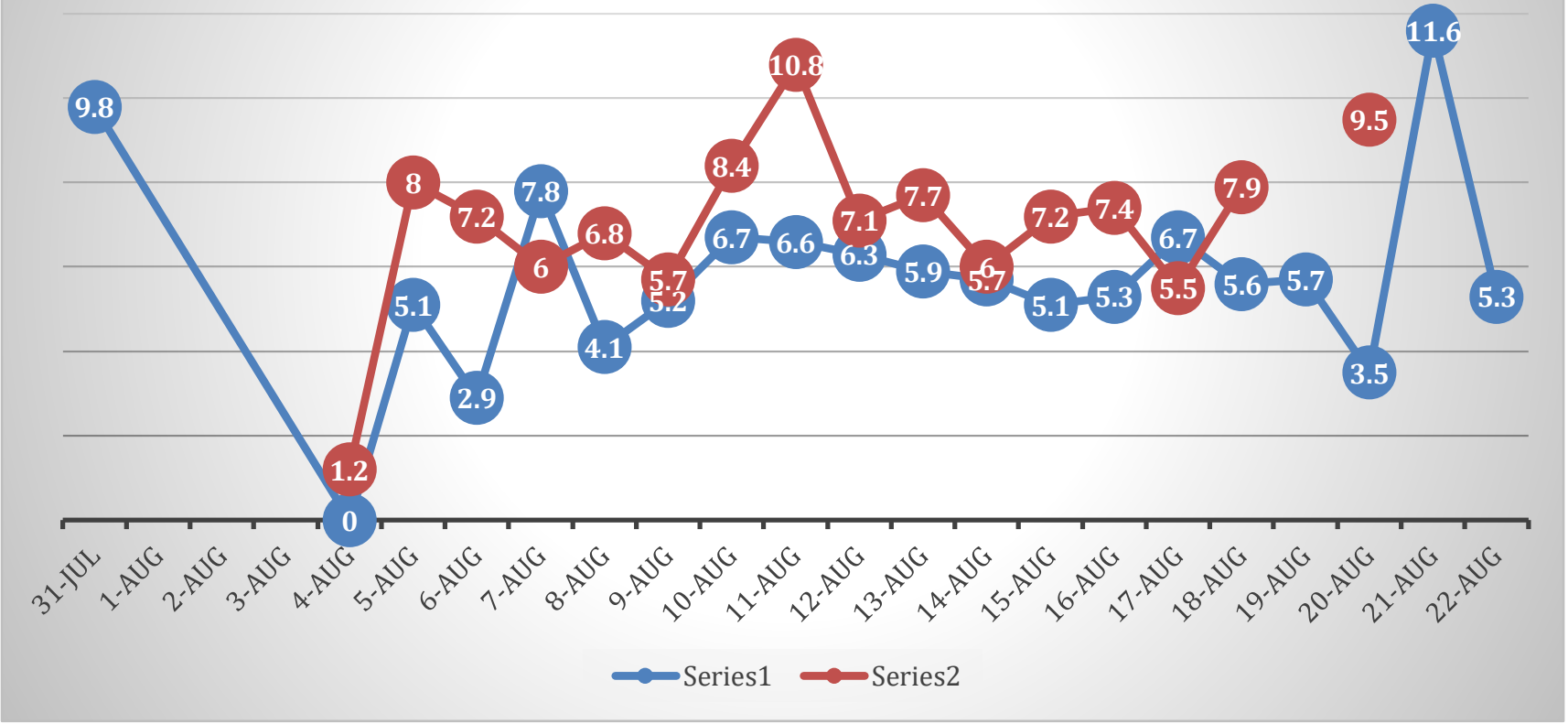

